\title{
Perpetual Digital Literacy
}

\author{
Martha Rotter ${ }^{1}$ \\ Microsoft
}

(Received March 2014; final version received September 2014)

Digital Literacy today means something very different from what it did ten years ago, five years ago, last year and maybe even last month. When I was growing up in the 80s, it meant that you could use the clunky search machines at the local library, and possibly that you had to take touch typing classes in school. In the 90s it evolved into being able to use a word processor and email. And in the last twelve years, it has come to mean everything from browsing the internet to buying goods online to using social media (and not putting your job in jeopardy by doing so!). Today's new hires will be expected to be proficient at using tablet computers and e-reader devices, and to be able to do a lot of their job on the go using a phone more powerful than laptops from only five years ago.

Since the definition of digital literacy changes constantly, there is no way to standardize on it. Instead, I propose we focus on the term "Perpetual Digital Literacy" and define it as a constant effort to improve our ability to communicate in the current technology environment. I am an advocate of perpetual digital literacy because it does not concern itself with learning some finite, subset of knowledge. Instead, it focuses on learning how to learn, which is a much more valuable skill. Technology will outdo itself every year for the rest of our lives. Don't plan on "catching up," or you will be endlessly frustrated, feeling like you're running to stand still. Instead, focus on learning how to learn.

Are you panicking a little? It sounds like we have a lot to do, and a lot more to learn. Metacognition is defined as "cognition about cognition", or "knowing about knowing." Some evolutionary psychologists have hypothesized that metacognition has been used as a survival tool. If that's true, then learning to learn is not anything new, it is a skill humans have nurtured and cultivated for a very long time. The reason it feels somewhat wrong to have to continually update our skills might be because we are accustomed to a traditional education structure: we identify an interest, we study it, we learn it all and we get a degree certifying that we have mastered the area. Following that process, we are a subject matter expert.

However this format for education is not best suited to subject matter like this which changes so quickly.

So how do we learn how to learn? And equally important, how we do teach this skill in the classroom to our own students? Learning how to learn can be broken down into three components:

1. Awareness

2. Relevance

\footnotetext{
${ }^{1}$ Corresponding author. Email:
} 


\section{Application}

Awareness: To be able to learn about new technology, we must first enable ourselves to be aware of it. What are your sources of news, of insights, of interesting approaches? Catalogue them and find a tool that starts bringing them into view on a weekly or bi-weekly basis. What communities are you a part of that contribute to your awareness? With whom can you discuss trends, changes and interesting developments? Good sources might be particular blogs, news sites, conference papers or even Twitter. Twitter often has educational chats using hashtags, find one that is relevant for you.

EXERCISE - Take five minutes and quickly write down as many sources you can think of that you have used in the last couple of months. Write them down along with a note about where it came from: was it something you've been following for a while or did a friend or colleague point you to it, did you spot it on a social network, in a newsletter. Now go through the list and determine which of the sources you have gone back to since or continued to follow. Determine which of these you might be able to incorporate into a news routine.

Relevance: Not everything we hear about in passing is relevant to us, our scenario, our students. Setting up filters is a way of reducing your signal-to-noise ratio so that the things you investigate are actually relevant and useful for you. Don't be afraid to cull blogs that aren't providing value for you or unfollow people on Twitter that are negative or not helpful. People often spend a lot of time reading useless information. Your time is worth more than that. Treat your time as a precious resource and do not waste it reading content that depresses or drains you.

EXERCISE - Find a tool that helps you skim content better. Try Google Reader, Feed.ly, the Reeder iOS app or others to help you flip through your sources quickly and discard those that are irrelevant to your work. Try the same on Twitter if you're using it. Set up lists of individuals, organisations and hashtags you wish to follow and check those once a day rather than trying to stay on top of everyone's tweets all the time.

Application: The last step is application. Once a relevant technology, skill, device or tool is identified, now is the phase where you can put it in to practice. Find a course, either online or in-person to learn more about it. Block off two hours and dive in yourself. Make it a class activity where everyone tries it together.

EXERCISE - Pick a reasonable timeslot for yourself individually, and one for your class if it's appropriate. It can be weekly, monthly, quarterly, whatever works for you. The goal is to ignore everything else for that timeslot and focus on trying to learn something new. If it's you individually, perhaps you want to spend a half hour each week trying different techniques for storing course documents online until you find one that suits best. Or maybe you plan to spend one day each month learning how to set up a blog or email newsletter for your class. Group activities might be something like a half day every other week using a social learning portal, or creating and uploading videos of something students would like to teach others. Or maybe it is two days each month using collaborative learning technology and talking with classrooms on the other side of the world, sharing what you're learning. Students will have ideas of what would be interesting and what they would like to learn, and activities like this are engaging and encourage cooperation as well. 
Combining these three steps will allow you to constantly have an ear open for practices that can help you and technologies that may be useful for your teaching or for your students. As an example, I use Google Reader to capture several blogs I choose to follow, the Reeder app on iPad to quickly parse out the posts I want to read or spend more time with, Instapaper for longer articles, and both Kippt.com and pinboard.in to store and share links. I share these links occasionally as recommended reading for classes I'm teaching, as project ideas for students, and as tutorials for those wishing to learn more about a certain area.

The things I want to spend my time learning change constantly, but I am careful to block out at least a small bit of time for myself to read and try new things every week.

Essentially, perpetual digital literacy is about embracing the idea that I will never know everything, but that I can focus on finding and learning the most important and relevant skills for me to do my job. Building perpetual digital literacy into my goals and workflow is something I can do to make sure the students I teach are prepared for a world that will never stop changing.

\section{Resources:}

Wikipedia - Metacognition http://en.wikipedia.org/wiki/Metacognition Wright, Frederick. APERA Conference 2008. 14 Apr. 2009.

\section{Tools:}

Google Reader - http://google.com/reader

Twitter - http://twitter.com

Reeder app for iOS - http://reederapp.com/

Feedly RSS Reader - http://www.feedly.com/

Kippt link sharing - http://kippt.com

Pinboard link sharing -http://pinboard.in/

Instapaper reading tool - http://www.instapaper.com 